\title{
Diensthabende
}

\section{Sportsfreunde aufgepasst!}

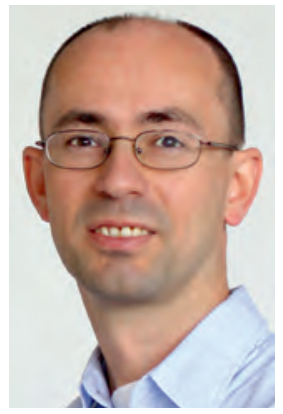

Ärzte und Sportler - die beiden verstehen sich sehr oft prächtig. Beide sind fasziniert vom menschlichen Körper und geprägt von der Leidenschaft, in ihrer „Disziplin“ verdammt gut zu sein. Ist diese innere Verwandtschaft auch der Grund, warum Sportmediziner zu den zufriedensten Ärzten gehören? In unserem Artikel „Athleten mit Approbation“ (S. 20) stellen wir Vertreter dieses Faches vor - alle sind mit Begeisterung Ärzte und Sportler, und man merkt, dass sie gerade diese Kombination glücklich macht. Doch Vorsicht! Bei aller „sportlicher“ Leistungsbereitschaft sollten Ärzte nicht vergessen, dass es auch einen entscheidenden Unterschied gibt: Wenn Sportler sich verausgaben, verbrennen sie Fett. Wenn Mediziner sich verausgaben, brennen sie aus. Das gilt auch schon fürs Studium. Verwechseln wir unseren Job also - bei allem Spaß und aller Leidenschaft - niemals mit einem Marathonlauf. Die Medizin ist kein Wettkampf, und kein junger Mediziner wird disqualifiziert, weil er mal einen Umweg geht oder zwischendrin o̊ํำ
In diesem Sinn: Eine frohe Vorweihnachtszeit! Euer Dieter Schmid

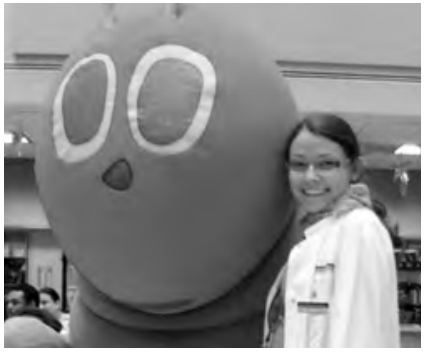

Dr. Victoria Ziesenitz arbeitet in der Pädiatrie in Heidelberg. In ihrem PJ in den USA war sie mit vielen adipösen Patienten konfrontiert (hier mit der Raupe Nimmersatt). In diesem Heft kümmert sie sich um besonders kleine Patienten und beschreibt die Erstversorgung von Neugeborenen (Seite 30).

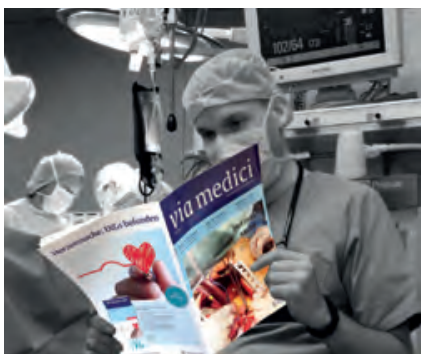

Daniel Marx

ist Anästhesist und Notfallmediziner mit einem Faible für „Human Factors" in der Akutmedizin. In seinem Artikel gibt er einen Einblick in die menschlichen Verhaltensweisen unter Stress und die Risiken von Selbstüberschätzung und reduzierter Wahrnehmung (Seite 26).

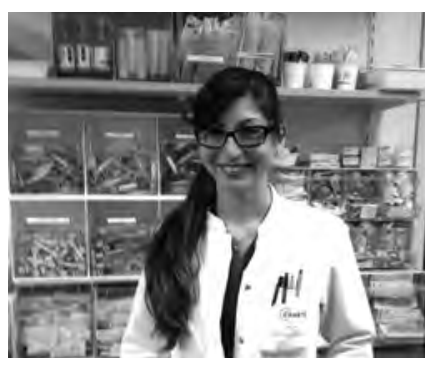

Güliz Parmaksiz

ist Assistenzärztin in der Klinik für Neurochirurgie der Charité in Berlin. In der klinischen Forschung interessiert sie sich für zerebrovaskuläre Erkrankungen. In diesem Heft stellt sie uns einen spannenden „Kolibri“ aus diesem Bereich vor: die Moyamoya-Krankheit (Seite 40). 